\title{
Strong correlation between prevalence of severe vitamin D deficiency and population mortality rate from COVID-19 in Europe
}

\author{
Isaac Z. Pugach · Sofya Pugach
}

Received: 19 August 2020 / Accepted: 11 February 2021 / Published online: 15 March 2021

(C) Springer-Verlag GmbH, AT part of Springer Nature 2021

\begin{abstract}
Summary
Background Severe acute respiratory syndrome coronavirus 2 (SARS-CoV-2) causes a very wide range of disease severity: from completely asymptomatic to fatal, and the reasons for that are not well understood; however, there are some data that show vitamin D may have a protective effect.

Methods To retrieve the vitamin D levels data, the authors analyzed the vitamin D European population data compiled by 2019 European Calcified Tissue Society (ECTS) statement on vitamin D status published in the European Journal of Endocrinology. For the data set to be used for analysis, only recently published data that included general adult population of both genders aged 40-65 years or wider and must have included the prevalence of vitamin $\mathrm{D}$ deficiency.

Results There were data sets from 10 countries that fitted the criteria and were analyzed. Severe vitamin D deficiency was defined as $25(\mathrm{OH}) \mathrm{D}$ less than $25 \mathrm{nmol} / \mathrm{L}(10 \mathrm{ng} / \mathrm{dL})$. Pearson correlation analysis between death rate per million of population from coronavirus disease 2019 (COVID-19) and prevalence of severe vitamin D deficiency showed a strong correlation with $\mathrm{r}=0.79, p=0.007$. Over time, correlation strengthened, and $\mathrm{r}$ coefficient asymptotically increased. After adjusting for countries' age structure and per capita health expenditures, multiple linear regression analysis showed that higher prevalence of severe vitamin D deficiency is associated with in-
\end{abstract}

Isaac Pugach acts as corresponding author before and during publication. After publication, please direct all queries to Sofya Pugach as corresponding author.

I. Z. Pugach, M.D. ( $\varangle)$ · S. Pugach, M.D., Ph.D., MPH ( $\bowtie)$ Complete Med Care, Forest Lane, Dallas, TX 8989, USA izpugach@yahoo.com

S. Pugach, M.D., Ph.D., MPH ( $\bowtie)$

drpugach@yahoo.com creased mortality. Each $1 \%$ increase in prevalence increased deaths by 55 per million (95\% confidence interval, CI 8-102), $p=0.03$.

Conclusion The authors recommend universal screening for vitamin D deficiency, and further investigation of Vitamin D supplementation in randomized control studies, which may lead to possible treatment or prevention of COVID-19.

Keywords Prevention - Protective effect - Death rate SARS-CoV-2 $\cdot$ Coronavirus

\section{Introduction}

Severe acute respiratory syndrome coronavirus 2 (SARS-CoV-2) causes a very wide range of disease severity: from completely asymptomatic to fatal, and the reasons for that are not well understood; however, there are some data that show vitamin D may have a protective effect [2].

\section{Methods}

The authors analyzed European countries vitamin D data compiled by 2019 ECTS statement on vitamin D Status published in the European Journal of Endocrinology [4]. For the data set to be used for analysis, it must have been published in the last 10 years, must have included general adult population of both genders aged 40-65 years or wider, and must have had breakdown on the prevalence of vitamin $\mathrm{D}$ deficiency.

Deaths from coronavirus 2019 (COVID-19) data were retrieved from the John Hopkins University of Medicine Coronavirus Resource Center [4]. Demographics data for 2020 were retrieved from the CIA World Factbook [1]. Healthcare expenditures were retrieved from UN data [6]. Six data retrievals were performed between 11 May 2020 and 4 August 2020. 
Fig. 1 Prevalence of severe vitamin $D$ deficiency vs COVID-19 deaths/million in Europe

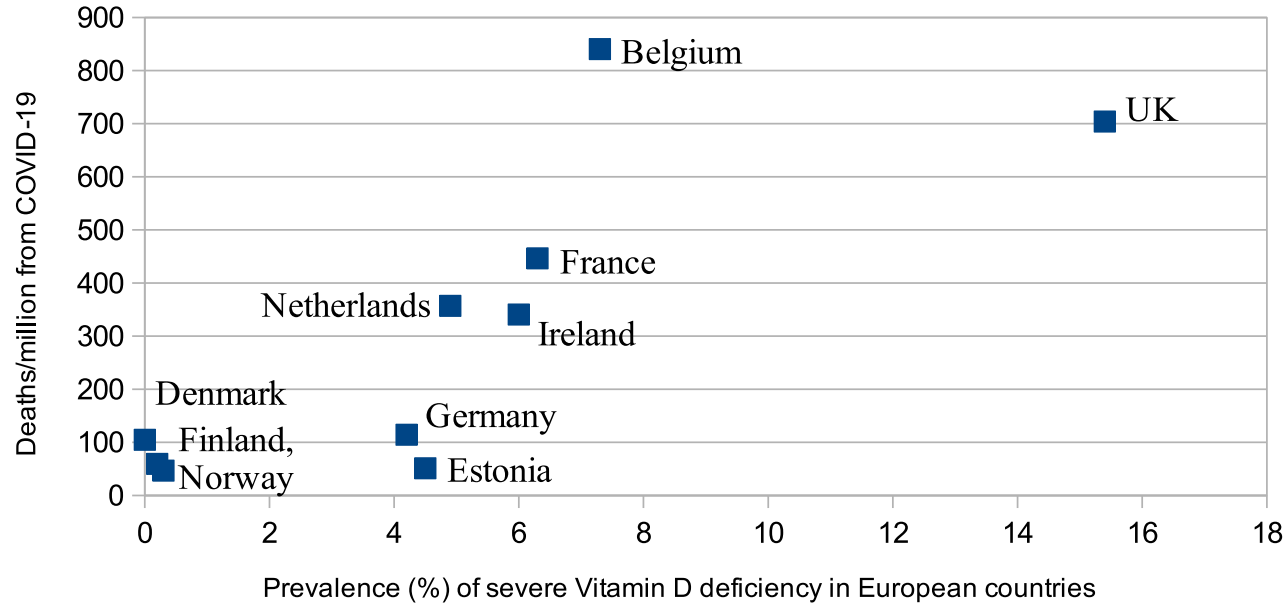

Pearson correlations and multiple linear regression analysis were performed on the data using LibreOffice Calc version 6.3 software (Free Software Foundation Europe [FSFE], Berlin, Germany).

\section{Results}

Table 1 shows vitamin D, demographic, health expenditures, COVID-19 death data and corresponding Pearson correlation statistics for the 10 European countries. Figure 1 graphically displays the relationship between deaths/million from COVID-19 and the prevalence of severe vitamin D deficiency.

Correlation analysis showed that countries' prevalence of severe vitamin D deficiency (serum vitamin $25(\mathrm{OH}) \mathrm{D}$ less than $25 \mathrm{nmol} / \mathrm{L}$ ) is strongly and significantly correlated with COVID-19 deaths per million of the population with $\mathrm{r}=0.79, p=0.007$. Correlation coefficient asymptotically increased from 11 May
2020 to 4 August 2020: $0.70 \rightarrow 0.72 \rightarrow 0.75 \rightarrow 0.76 \rightarrow 0.78$ $\rightarrow 0.79$.

After adjusting for countries' age structure and per capita health expenditures, multiple linear regression analysis showed that higher prevalence of severe vitamin D deficiency is associated with increased mortality. Each $1 \%$ increase in prevalence increased deaths by 55 per million (95\% confidence interval, CI 8-102, $p=0.03)$.

\section{Discussion}

Data collected shows a strong and significant correlation between prevalence of severe Vitamin D deficiency and COVID-19 deaths per million in European countries. The correlation is asymptotically getting stronger over time, making it even less likely to be caused by a random chance. This is consistent with US and UK trends that show the mortality rate from COVID-19 is higher in dark-skinned and obese indi-

Table 1 European countries vitamin D, demographic, healthcare expenditures, COVID-19 death data and the correlation with COVID-19 deaths/million [1, 4, 6]

\begin{tabular}{|c|c|c|c|c|c|c|c|}
\hline Country & $\begin{array}{l}\text { Prevalence (\%) of Vit. D } \\
<25 \mathrm{nmol} / \mathrm{L}\end{array}$ & $\begin{array}{l}\text { Prevalence (\%) of Vit. D } \\
<50 \mathrm{nmol} / \mathrm{L}\end{array}$ & $\begin{array}{l}\text { Mean }(\mathrm{nmol} / \mathrm{L}) \\
\text { Vitamin D }\end{array}$ & $\begin{array}{l}\text { Median } \\
\text { Age }\end{array}$ & $\begin{array}{l}\text { Over age } 65 \\
(\%)\end{array}$ & $\begin{array}{l}\text { Health spending per } \\
\text { capita in US\$ }\end{array}$ & $\begin{array}{l}\text { COVID-19 deaths/ } \\
\text { million }\end{array}$ \\
\hline UK & 15.4 & 56.4 & 47.4 & 40.6 & 18.5 & $\$ 3648$ & 704 \\
\hline France & 6.3 & 34.6 & 60 & 41.7 & 20.5 & $\$ 4690$ & 447 \\
\hline Belgium & 7.3 & 51.1 & 49.3 & 41.6 & 19.2 & $\$ 4711$ & 840 \\
\hline Germany & 4.2 & 54.5 & 50.1 & 47.8 & 23.0 & $\$ 4683$ & 114 \\
\hline Netherlands & 4.9 & 33.6 & 59.5 & 42.8 & 19.8 & $\$ 5737$ & 357 \\
\hline Ireland & 6 & 45 & 56.4 & 37.8 & 13.8 & $\$ 3709$ & 341 \\
\hline Denmark & 0 & 23.6 & 65 & 42 & 19.9 & $\$ 6304$ & 105 \\
\hline Finland & 0.2 & 6.6 & 67.7 & 42.8 & 22,3 & $\$ 4232$ & 59 \\
\hline Norway & 0.3 & 18.6 & 65 & 39.5 & 17.4 & $\$ 9055$ & 47 \\
\hline Estonia & 4.5 & 51 & 51.6 & 43.7 & 21.0 & $\$ 1010$ & 51 \\
\hline \multicolumn{8}{|l|}{$N=10$} \\
\hline $\begin{array}{l}\text { Correlation coeffi- } \\
\text { cient }\end{array}$ & 0.79 & 0.53 & -0.58 & -0.29 & -0.28 & -0.15 & - \\
\hline T-statistics & 3.63 & 1.75 & -2.03 & -0.87 & -0.83 & -0.42 & - \\
\hline$P$-value & 0.007 & 0.12 & 0.08 & 0.41 & 0.43 & 0.68 & - \\
\hline
\end{tabular}


viduals than in general population, as these individuals are at higher risk for vitamin $\mathrm{D}$ deficiency.

Since the correlation coefficient $r=0.79$, it means that about $62 \%\left(\mathrm{r}^{2}\right)$ of deaths from COVID-19 can be explained by prevalence of severe vitamin $\mathrm{D}$ deficiency. This finding by itself does not necessarily mean causality, or that correcting deficiency would decrease the mortality, because another variable could cause both high prevalence of vitamin D deficiency and increased deaths from COVID-19. Examples of such variable could be prevalence of unknown genetic variation or certain healthcare system variations.

However, since there are data that show vitamin D deficiency is associated with greater risk of various infections [3] and that vitamin D supplementation could reduce risk of COVID-19 infections [2], it is very likely that vitamin $\mathrm{D}$ supplements have a large role in prevention and possibly treatment of COVID-19. Supporting this theory, Nordic countries' population have low prevalence of vitamin D deficiency as a result of recent campaigns for common use of supplements, cod-liver oil and vitamin D fortification [5], which may also explain low COVID-19 death rate (Sweden is a notable exception due to completely different infection control approach).

\section{Conclusion}

There is a strong correlation between prevalence of severe vitamin $\mathrm{D}$ deficiency and the mortality rate per million from COVID-19 in the European countries. The authors recommend for physicians to universally screen for vitamin D deficiency, and recommend further investigation of vitamin D supplementation in randomized control studies, which may lead to possible treatment or prevention of COVID-19.

Conflict of interest I. Z. Pugach and S. Pugach declare that they have no competing interests.

\section{References}

1. CIA. World factbook. https://www.cia.gov/library/ publications/the-world-factbook. Accessed 4 Aug 2020.

2. GrantWB, LahoreH, McDonnellSL, etal. Evidence that vitamin D supplementation could reduce risk of Influenza and COVID-19 infections and deaths. Nutrients. 2020;4:988-93.

3. Gunville C, Mourani P, Ginde A. The role of Vitamin D in prevention and treatment of infection. Inflamm Allergy Drug Targets. 2013;12(4):239-45.

4. JohnHopkins University of Medicine. Coronavirus resource center. https:// coronavirus.jhu.edu. Accessed 4 Aug 2020.

5. Lips P, Cashman KD, Lamberg-Allardt C, et al. Current vitamin D status in European and Middle East countries and strategies to prevent vitamin D deficiency: a position statement of the European Calcified Tissue Society. Eur J Endocrinol. 2019;4:23-54.

6. UN. Data. http:// data.un.org. Accessed 4 Aug 2020.

Publisher's Note Springer Nature remains neutral with regard to jurisdictional claims in published maps and institutional affiliations. 